\title{
Temporary Measures: Canadian Refugee Policy and Environmental MigRATION
}

\author{
Eric OMeziri and Christopher Gore
}

\begin{abstract}
In 2010, 42 million people worldwide were displaced from their homes as the result of environmental factors. These "environmental migrants" lack international recognition and have no recourse to the protections of the international refugee regime. Given Canada's history of international refugee resettlement, this paper examines Canada's past and potential response to environmental migrants. Evidence reveals that the Canadian government relies on ad hoc, temporary measures, and that clear, long-term policy measures for issues surrounding forced migration due to environmental events are unlikely. The implications of this outcome are discussed, providing observations and lessons for researchers and advocates of migration rights.
\end{abstract}

\section{Résumé}

En 2010, 42 millions de personnes à travers le monde on été déplacées pour des causes environnementales. Ces "migrants environnementaux» ne sont pas reconnus sur le plan international et nont donc pas de recours possible en vertu du régime international des réfugiés. Compte tenu de l'histoire canadienne en matière de réinstallation de réfugiés au niveau international, cet article examine les réactions canadiennes passées et futures à la migration environnementale. Les données montrent que le gouvernement canadien se fie sur des mesures temporaires, ad hoc, et qu'il est peu probable qu'il mette en place des mesures et des politiques à long terme répondant aux problèmes liés à la migration environnementale forcée. On y discute des implications de ces résultats, tout en offrant des observations et des conclusions pouvant intéresser les chercheurs et les avocats en droit de la migration.

$$
\begin{array}{r}
\text { Tens of thousands of mostly poor people have died. Tens of } \\
\text { millions have been temporarily or permanently displaced } \\
\text {... We must, above all, shift from a culture of reaction to a } \\
\text { culture of prevention. } \\
- \text { Kofi Annan1 }
\end{array}
$$

\section{Introduction}

Each year, humanitarian crises worldwide displace millions of people from places that once provided them with shelter, livelihood, and a sense of community. With little time to plan and few available resources, affected individuals and families, even entire villages, must move in response to the deterioration of their natural environment and at times cross international boundaries into neighbouring countries to seek safety. Described as a global phenomenon, "environmental migration" has the potential to affect a significant number of individuals. ${ }^{2}$ While the effects are far-reaching, certain regions are especially vulnerable to environmentally induced population displacement. Factors such as a high population density, combined with a drought- or floodprone climate, or proximity to a geographic risk factor such as an active fault line increase the risk of environmental displacement. Areas especially at risk for large-scale environmental migration are the Himalayan region, which may face severe water shortages due to glacial retreat, Pacific island states, and the drylands of Central America where considerable vulnerability to both drought and severe weather in the form of hurricanes exists. The Nile, Ganges, and Mekong River delta regions are also particularly at risk for major flooding, e.g., the flooding of large sections of Bangladesh 
that displaced thousands during the 2010 monsoon season. In addition, the Sahel and Great Lakes regions of Africa are particularly at risk and have experienced acute and gradual environmental declines leading to migrations as a result of droughts and intensive land degradation. ${ }^{3}$ In 2010, an estimated 42 million people were displaced from their homes as the result of immediate and long-term changes in the physical environment ${ }^{4}$-a figure that is roughly equal to the number of people displaced by war and persecution during the same period. ${ }^{5}$ By the year 2050, the total estimated number of people likely to be displaced by changes in the biophysical environment is expected to reach 200 million, with some research indicating that the total number could be as high as 700 million. ${ }^{6}$

Multiple terms have been used to describe groups of individuals that are forced to move or choose to move in response to changes in their physical environment. Examples of terms used include environmental migrant, environmental refugees, and environmentally displaced people. Convention refugees, as defined by the 1951 United Nations Convention relating to the Status of Refugees, are displaced persons who are offered a measure of protection by the international refugee regime. If, however, the cause of their displacement is due to an advancing drought, natural disaster, land loss, degradation, or other environmentally related factors, migrants may find that no guarantees of protection exist and they may be faced with the possibility of returning to a country they had once fled to confront a very uncertain future. In the long term, the indirect effects of climatic change are expected to increasingly influence human migration. ${ }^{7}$

In this paper we use the term environmental migrant to describe individuals or communities of people that must move or choose to move from a location as the result of changes in their biophysical environment. Migration resulting from immediate changes to the biophysical environment due to an acute event such as a natural disaster, or from long-term changes that cannot be directly rectified or mitigated by policy interventions are circumstances that would be classified as "environmental migration" in this context. This understanding of environmental migrant does not eliminate other intervening variables as causal explanations for migration. However, this paper suggests that migration caused by a clear shift in an individual's or communities' biophysical environment (for example, access to land for housing is removed, the quality of soil is irrevocably harmed or ability to produce food is eliminated, or access to necessary resources for survival like clean water are permanently disrupted) warrants the classification of environmental migration. This understanding conforms to the definition of environmental migrant advocated by the
International Organization for Migration and elaborated below.

Given this context, this paper examines how and if national governments, particularly ones that are high immigrant- and refugee-receiving countries, are responding to environmental migrant populations. Owing to Canada's historical role in international debates and policy development concerning migrants and refugees, and its legacy and reputation as a high immigrant- and refugee-receiving country, this paper asks two questions: How has Canada responded to forced migration and environmental migration events? And what does this experience teach us about the prospects for future responses to environmental migration?

Historically and in the very recent past, Canada has responded to incidences of forced migration with policy directives that have facilitated migration to Canada, provided status to migrants already in the country, expedited immigration processing, and provided other benefits to displaced persons if they have fallen within certain defined categories. Temporary and ad hoc, these policy directives allow policy-makers and the national government to make decisions on a case-by-case basis and to be flexible in the face of incidences of forced migration. This approach also has its drawbacks, however, and at times the result has been piecemeal policy development that amounts to a "wait and see" approach to the issue of forced migration. The few policy measures that are currently in place in Canada are not comprehensive and leave important decisions regarding the processing of individuals affected by disasters up to the discretion of individual immigration officers. ${ }^{8}$ For example, Canada contributed to the relief effort in Haiti following the 2010 earthquake. The government issued policy directives after the earthquake as a temporary way of facilitating Haitian migration to Canada. These directives, a result of a natural disaster, were developed directly and solely in response to the event in Haiti and were not part of a broader policy or strategy relating to environmental migration generally. Does Canada's response to the earthquake in Haiti illustrate its present and future policy to environmental migration? Or will this event, other potential natural disasters, or expected migration due to environmental change lead Canada to develop a clearer policy and position on its response to and treatment of environmental migrants?

Using the events in Haiti, this paper argues that temporary, ad hoc policy directives will likely remain the principal response to environmental migration by Canada in the future. The immigration policy directives issued following the Haitian earthquake demonstrate the current state of environmental migration policy in Canada, which, arguably, is based on ad hoc, temporary measures, as opposed to a stable long-term approach. While it can be argued that this 
approach allows for flexibility and a considered response to global migration needs on a case-by-case basis, it does not provide any clear national or global indication of how and if Canada will respond to future events of environmental migration. The absence of a position or policy provides no assurance to environmental migrant or refugee advocates about how the government will respond to future incidences of displacement, provides little guidance to individual immigration and refugee officers, leaving them to make decisions about admittance to Canada based on temporary, ad hoc policies, and priorities, and will do little or nothing to assist the international community in its future response and protection of environmental migrants.

This paper continues by first discussing environmental migration and its general relationship to refugee policy, including Canadian refugee policy. The paper then examines the response to the 2010 Haitian earthquake, which illustrates why Canada has addressed and likely will continue to address environmentally caused migration on a case-by-case basis.

\section{Environmental Migration: The Conceptual Challenge}

Considerable effort has been devoted to developing a definition of environmental migration that can gain international recognition and encompass the range of environmentally induced circumstances that lead to forced migration. Prominent international organizations such as the International Organization for Migration and the United Nations University (UNU) have voiced their support for granting international recognition to environmental migrants. UNU-Environment and Human Security Director Janos Bogardi has stated, "There are well-founded fears that the number of people fleeing untenable environmental conditions may grow exponentially as the world experiences the effects of climate change and other phenomena ... this new category of 'refugee' needs to find a place in international agreements. We need to better anticipate support requirements, similar to those of people fleeing other unviable situations." 9 Borgardi's statement falls short of calling for the sort of recognition granted to convention refugees; however, it does underscore the international community's inability to find a place for environmental migrants within the existing protection framework for displaced persons. On its own, the international recognition of environmental migrants does not directly address the consequences of environmental migration; however, it is viewed as a useful policy objective for its ability to support other policy initiatives. Often international aid is directed to issues that have the backing of a constituency that can exert political pressure. ${ }^{10}$ Accordingly, international recognition of environmental migrants could be an important step towards developing an environmental migrant constituency that could direct resources and institutional support towards their particular needs.

United Nations Environment Programme researcher Essam El-Hinnawi is often credited with first attributing the term environmental refugee to individuals who have been displaced as a result of environmental causes. In 1985, El-Hinnawi described environmental refugees as "those people who have been forced to leave their traditional habitat, temporarily or permanently, because of a marked environmental disruption (natural and/or triggered by people) that jeopardized their existence and/or seriously affected the quality of their life. By 'environmental disruption' in this definition is meant any physical, chemical, and/ or biological changes in the ecosystem (or resource base) that renders it, temporarily or permanently, unsuitable to support human life."11 The term environmental refugee has since become popularized, perhaps as a result of the term's ability to draw parallels between the more familiar circumstances of political refugees fleeing persecution and the plight of individuals displaced by some form of degradation to their natural environment. The term environmental refugees evokes images of people fleeing devastation due to a natural disaster or other environmental catastrophe, and it is perhaps for that reason that the term has gained currency in the media and the wider public consciousness. From a policy perspective, there is also a potential benefit to the notion of an environmental refugee. Associating migration induced by environmental or biophysical conditions with conventional refugees might allow environmental refugees to benefit from the same kinds of protections offered by the international refugee-protection regime already in place. However, in practice this has not occurred. Despite initial attempts to better define the concept of an environmental refugee, use of the term is contentious, and there remains no general agreement on how to classify people displaced as the result of changes in their environment. There are several reasons for this ambiguity.

First, the term refugee carries a legal designation established by the 1951 Convention relating to the Status of Refugees. A refugee under the provisions of the convention is defined as "a person who owing to a well-founded fear of being persecuted for reasons of race, religion, nationality, membership of a particular social group or political opinion, is outside the country of his nationality and is unable or, owing to such fear, is unwilling to avail himself of the protection of that country; or who, not having a nationality and being outside the country of his former habitual residence as a result of such events, is unable or, owing to such fear, is unwilling to return to it." 12 The refugee convention makes 
no mention of the environment as a possible factor inciting forced migration from an area of residence, thereby excluding environmental migrants.

Second, the refugee convention is concerned with addressing circumstances of forced or involuntary migration-circumstances in which people could not reasonably choose to stay within their country of origin. The degree of volition involved in an individual instance of migration due to environmental circumstances generally exists on a continuum that is often very subjective: at one end of the continuum, the migration is involuntary, e.g., displacement due to floods or earthquakes, while on the other end of the continuum, the decision to migrate could be voluntary, e.g., inhabitants determine that the biophysical conditions are too poor and difficult to permit a livelihood to be sustainable and therefore migrate. There have been several attempts to develop a classification that defines what constitutes voluntary environmental migration versus the involuntary variety; the work of Diane C. Bates is one example. ${ }^{13}$ However, it has proven difficult to make clear distinctions between the two. Even in the event that it were possible to classify environmentally induced migration more clearly, any effort to classify people migrating in response to environmental conditions as "refugees" is still impeded by the wording of the refugee convention, which requires that a person claiming to be a refugee experiences a form of persecution.

Finally, and perhaps most significantly, the majority of those displaced due to environmental causes do not cross an international border; rather, they are displaced internally and remain within the confines of their own country and therefore would not be the focus of any policies or programs designed to assist convention refugees. ${ }^{14}$

The issues noted above represent a significant challenge to a stronger international protocol or national policy relating to environmental migration. The challenge is particularly high if there is a desire to include environmentally displaced people under the current international refugee protection regime. Still more disheartening for environmental migrant advocates is the possibility that the "environmental refugee" concept is having a paradoxical effect, as refugee-receiving countries are seeking to limit their obligations under the refugee convention in order to avoid responsibility for an anticipated "flood" of environmental refugees. ${ }^{15}$ It seems that conflating environmental refugees with political refugees is blurring the already well-established line of who has the legal right to seek asylum, thus potentially threatening the asylum process of convention refugees instead of enlarging the refugee regime to include the environmentally displaced. In an effort to maintain the rights available to refugees under the current refugee protection regime and to develop a concept that is more encompassing of the multifaceted character of environmental migration, a number of alternative terms have been suggested, each with its own strengths and weaknesses.

Among the terms that appear in the environmental migration literature are ecomigrant, which demonstrates the link between the economic and ecological factors that influence migration. ${ }^{16}$ Another concept is environmentally displaced person (EDP), which is useful for its similarity to internally displaced person (IDP), a displaced-persons category that has gained a degree of recognition through international "soft law" such as the Guiding Principles on Internal Displacement. ${ }^{17}$ Within contemporary writing, environmental migrant is a term that has also gained a high level of support. The International Organization for Migration (IOM) has adopted the term and has put forward the following definition: "Environmental migrants are persons or groups of persons who, for compelling reasons of sudden or progressive change in the environment that adversely affects their lives or living conditions, are obliged to leave their habitual homes, or choose to do so, either temporarily or permanently, and who move either within their country or abroad." 18 The IOM definition establishes that the environment can be a critical factor that influences an individual or group to migrate. The language used in the definition addresses acute, short-term displacement as well as chronic, long-term displacement and takes into account the internally displaced in addition to those displaced across international borders. Further, the environmental migrant concept, as it is defined by the IOM, accounts for the multivariate nature of environmental migration and allows for a range of environmental migration circumstances. It has been noted that the IOM definition is limited by its omission of language that distinguishes between voluntary and forced migration; it also does not identify which state or non-state institution is responsible for the persons displaced. ${ }^{19}$ However, it would be difficult for any definition to completely account for the myriad circumstances that constitute environmental migration.

In this paper, we accept that the term environmental migrant has the strongest and best utility globally. It encompasses immediate and prolonged changes in biophysical conditions that cannot be rectified or mitigated with policy or program interventions. As explained in the introduction, this does not eliminate the role that other factors could play in motivating migration, but it does emphasize that within instances of environmental migration the primary factor is an immediate or long-term pronounced change in the biophysical environment that renders the capability to maintain a sustainable livelihood impossible or extremely difficult. 
Researchers involved in the study of environmental migration argue that some form of international recognition of environmental migrants is an essential policy objective that must be met in order to gain wider support from the international community. ${ }^{20}$ Nevertheless, international recognition is only one aspect of a larger effort to address environmental migration. Ultimately, if a concept is to gain global acceptance in the international system, acceptance and support in nation-states are first required. Hence, the paper continues by considering examples of state-level policy initiatives that have been put in place to manage environmental migration in the absence of formal international recognition. For the purposes of this paper, various terms may be used interchangeably to refer to environmental migrants; however, the definition provided by the IOM should serve as the point of reference for all subsequent discussion.

\section{Canadian Immigration and Refugee Policy and Environmental Migration}

The causes of environmental migration are varied and interconnected. Consequently, occurrences of environmental migration present policy-makers with a set of challenges that span a wide array of policy areas. Policy-makers given the task of addressing incidents where populations have been displaced by natural events have several issues to consider. First, the decision of an individual to migrate in times of environmental change or disaster is usually based on a complex set of factors that often have as much to do with a potential destination offering greater opportunity for a livelihood as with the risk associated with staying in an environmentally degraded area. This is because the political, social, and economic environment in which migrants find themselves is often just as influential as the state of the natural environment. ${ }^{21}$ Second, policy relating to environmental migration does not just respond to an immediate event, but also has to address the likelihood of future events that could lead to forced migration. It should come as no surprise, then, that environmental migration gives rise to a broad set of policies found in areas as diverse as natural resource management, international development, environmental protection, economic development, and national security. ${ }^{22}$ However, it is not the aim of this paper to review the range of policies relating to the issue of environmental migration; rather, the discussion will centre on Canadian immigration and refugee policy as it relates to forced migration and environmental migration.

In the following sections, this paper first provides a general overview of migration and refugee policy in Canada. This paper then considers the case of the 2010 Haitian earthquake-a clear example of an environmental migration event. Together, these historic and recent events provide evidence to support the argument that temporary measures towards environmental migrants are likely to remain the standard practice.

\section{Canadian Refugee Policy: Historical Precedents}

Canadian immigration policy has prioritized international migration that best contributes to the country's economic growth. Be it settling the sparsely populated Canadian West for the purpose of agriculture during the nineteenth century, or the recent focus on attracting highly skilled immigrants and temporary foreign workers, Canada's tendency to relax admission requirements and allow large influxes of migrants usually occurs in conjunction with some form of economic imperative. Despite the overarching economic motivations associated with Canadian migration policy, immigration based on humanitarian factors has also played a significant role in the evolution of Canada's immigration system.

Canada's polices concerning refugee admissions were generally developed and implemented ad hoc until the country formally committed to the refugee convention in 1969. This step began the transition towards a formal process of granting protection to asylum seekers. However, there still exist large categories of displaced persons, e.g., environmental migrants or internally displaced persons, who are not covered under the formal refugee process. Furthermore, the Canadian government has taken steps to restrict the inflow of refugees under certain categories, with the stated reason being an effort to reduce the number of fraudulent asylum claims. For example, a provision of the recently enacted bill C-31, the Protecting Canada's Immigration System Act, establishes designated countries of origin (DCO). A DCO is deemed a country that does not normally produce refugees. Refugee claimants originating from DCOs are prohibited from applying for work permits and are denied health-care services under the Interim Federal Health Program (IFHP). In addition, while standard refugee claimants have 60 days to prepare their claims, DCO claimants must be prepared to present their claim within 30 days of their initial request for asylum. ${ }^{23}$ The expedited refugee process is intended to dissuade fraudulent claims, yet critics of Bill C-31 claim that the latest reforms to the Canadian refugee system deny rights to vulnerable refugee claimants. ${ }^{24}$ Given this context, how does the Canadian government respond at times when migrants are not persecuted but are displaced as the result of environmental events?

\section{Special Measures: The Canadian Response to the 2010 Haitian Earthquake}

The January 2010 earthquake, which struck near the Haitian capital city of Port-au-Prince, caused widespread 
destruction and thousands of deaths. It was a natural event made considerably worse by the economic and political instabilities of Haiti's recent past. High poverty, poor construction standards, an underdeveloped infrastructure, and a general lack of public services turned an earthquake of major proportions into a tragedy of catastrophic scale. To illustrate this point, the 1989 San Francisco earthquake that registered a magnitude of 7.0 on the Richter scale was equal in strength to the Haitian earthquake, yet the San Francisco earthquake caused 63 casualties, a fraction of the tens of thousands of lives lost in Haiti. ${ }^{25}$ While differences in natural risk factors explain some of the disparity between the casualty statistics of the Haitian and San Francisco earthquakes, the role that Haiti's political institutions, social conditions, and limited economic resources played in exacerbating the environmental catastrophe of 2010 are significant.

Despite the contributing factors, the displacement caused by the earthquake conforms to the definition of environmental migration. Norman Myers, an environmental migration researcher, notes that several decades of environmental and political mismanagement in Haiti have led to a situation where the majority of the Haitian population seeking asylum in other countries are doing so for environmentally related reasons, as opposed to the many who sought asylum from the persecution of authoritarian government during previous times in Haiti's turbulent history. ${ }^{26}$

In the aftermath of the earthquake, the Canadian government mounted a humanitarian response to the crisis. In addition to the financial and material resources provided by the Canadian government to assist with relief and reconstruction, Canadian migration policies played an important role in addressing the problems caused by disorganized environmental migration in Haiti. The Department of Citizenship and Immigration Canada (CIC) implemented several policies that facilitated the efforts of Haitian nationals who were seeking to enter or remain in Canada. The implementation of those policies was accomplished largely using operational bulletins, which CIC uses "in exceptional circumstances" to issue "one-time-only instructions or to provide urgent instructions to staff for a brief period." 27

Prior to the earthquake in Haiti, Operational Bulletin (OB) 83, "Guidelines for Priority Processing in the Event of Disaster Situations," was issued in 2008. The operational bulletin advises visa offices to use the discretionary powers granted to them by the Immigration and Refugee Protection Act to prioritize and expedite applications for permanent or temporary residence in Canada from countries affected by a natural disaster. OB 83 is a general operational directive. In effect, it is a reminder to visa offices that they possess the latitude necessary to respond to disasters in a "humane and expeditious manner." 28 CIC clearly states that $\mathrm{OB} 83$ is not a special program, nor priority processing, and it is the applicants' responsibility to demonstrate to the visa officer that they or their family members have been adversely affected by the disaster. In practice, OB 83 has not facilitated the migration of a significant number of displaced persons, since the responsibility of demonstrating the hardship caused by the disaster is placed on the affected individual, which may prove to be a significant barrier to entry into Canada, depending on the extent to which that person's life has been disrupted by the disaster. Moreover, beyond imprecise recommendations to exercise their delegated discretion, the bulletin provides minimal guidance to immigration officers making decisions on applications for permanent residency from individuals displaced by an environmental disaster. The outcome is a potential for a lack of consistency, as immigration offices and officers can interpret the merits of a natural disaster and its impact on applicants differently.

Following the Haitian earthquake, an additional operational bulletin was implemented to address the humanitarian crisis: OB 179, "Special Measures in Response to the Earthquake in Haiti." OB 179 instructed CIC officers to deliver immigration services to Haitian nationals that they might otherwise be ineligible to receive. In order to expedite the immigration process for Haitians seeking permanent residence in Canada, the special measures authorized the creation of the Ottawa Haiti Processing Office, which focused solely on processing immigration applications from Haiti. In addition, priority processing, fee exemptions, interim federal health coverage, as well as work and study permits were granted to selected Haitians seeking permanent residence. Further, a portion of the special measures addressed the ongoing adoption applications of Haitian orphans. The special program known as Operation Stork expedited the adoptions of Haitian orphans and evacuated several hundred Haitian children in the immediate aftermath of the earthquake. ${ }^{29}$

Policies intended to address the needs of Haitians already living in Canada were also a part of the Canadian government's response strategy. One such policy, the Temporary Suspension of Removals (TSR), suspended the deportations of Haitians who would otherwise be ineligible to remain in Canada. Unlike refugee status, which is granted on an individual basis according to the particular circumstance of the refugee claimant, TSR is a blanket protection available, with exception, to all nationals, from the designated country.

Predominantly clustered in the French-speaking city of Montreal, a significant Haitian diaspora community resides in Canada. The Canadian governor general at the time of the earthquake, Michaëlle Jean, herself a former refugee from 
Haiti, was very involved in bringing attention to the situation in Haiti after the earthquake. These factors may explain the Canadian government's willingness to use immigration and refugee policy to implement a significant humanitarian response to the disaster in Haiti, providing protection to thousands of displaced Haitians. Nevertheless, the temporary and ad hoc nature of the immigration programs put in place should cause some concern amongst advocates for displaced persons and environmental migrants.

Gaps in protection and vulnerabilities may develop as a result of the implementation of temporary, ad hoc directives. For example, representatives from organizations that work directly with refugees in Canada identified TSRs as an area of concern to a Standing Committee on Citizenship and Immigration in 2006. The committee participants noted that, while protected from immediate removal, displaced persons residing in Canada as a result of the TSR program are unable to become permanent residents, sponsor family members, and go on with their lives; they often work in lowpaying jobs and are limited in their access to health services and education. ${ }^{30}$ As a result, the benefits of temporary residency protection in the case of Haitians or any other future group affected by a natural disaster is low. Lacking the legal protections of convention refugees, environmental migrants with temporary forms of status may find that they receive protection from one context of vulnerability (the environmental disaster) only to find themselves confined to another (temporary residency with no clear timeframe and few services of support).

Special measures provide governments with the ability to offer protection to individuals who migrate internationally as the result of environmental events. The ad hoc nature and temporary duration of these policy instruments are appealing to governments, since special measures are adaptable policies that allow a government to prioritize humanitarian crises while keeping in mind other economic, security, and political considerations without being bound to a certain course of action by international law. However, those same characteristics have the potential to undermine the already precarious security of environmental migrants, as governments may use their discretion to select which disasters they respond to, on the basis of their affiliation with the affected country and its residents. Selecting migrants and accepting refugees in relation to "national affinity" is common. But in the midst of disasters where global support is needed, particularly from countries where immigration has been and is essential to a country like Canada, inconsistent, ad hoc, and temporary policy measures present serious concerns for a unified, global response to catastrophic events. For example, there was significant public debate regarding the discrepancy between Canada's robust humanitarian response following the Haitian disaster, and the relatively subdued response to large-scale flooding in Pakistan just a few months later. ${ }^{31}$

The Canadian government's response to humanitarian crises varies, yet one principle is consistent: at the time of unanticipated international events that cause mass displacement, the Canadian government has responded in an ad hoc manner. It has chosen to evaluate the events and develop a response in retrospect and often only after pressure has mounted on it to do so. For anyone hoping that the Canadian federal government might develop a clear and consistent policy position on the issue of displacement caused by environmental change, this legacy does not bode well. It also suggests that Canada is unlikely to take a lead in advancing a global position or protocol on environmental migration. Even though international bodies like the UNHCR or the International Panel on Climate Change (IPCC) can, and do, identify data and models suggesting the potential for increased human displacement from environmental change in the future, the problem remains that the Canadian government has a legacy of "waiting and seeing."

For better or worse, the "wait and see" policy approach has served national governments well, as each can align its migration and refugee policies and practices to its own preferences. In short, history suggests that even when the Canadian government has responded admirably to forced migration and refugee events in the eyes of international observers, it has still done so on a case-by-case basis. ${ }^{32}$ For forced migration events that are the result of political upheaval or conflict, this type of policy response may be understood. However, natural disasters occur regularly, and extreme weather events pose an increased threat, particularly for nation-states that are low-lying and prone to flooding or sea-level rise. ${ }^{33}$ The 2011 Foresight Report on migration and global environmental change notes that while no particular policy or set of policies can entirely mitigate the effects of migration due environmental change, polices that prepare for and respond to the effects of environmental migration can facilitate planned and coordinated movements while reinforcing the long-term resilience of communities and households. ${ }^{34}$ Hence, a clear, consistent policy position on environmental migration would seem to have merit. More clarity and consistency would offer migration and refugee advocates clarity on the likely actions of the government in future events and help them develop contingencies necessary to respond and assist; it would better ensure consistent actions between Canadian immigration offices and officers when responding to environmental migration events and emergencies globally; and it would put Canada in the lead in international discussions and debates 
surrounding environmental migration-debates that are surely going to become more important in response to the ongoing and increasing effects of climatic change.

\section{Conclusion: The Future of Canadian Policy concerning Environmental Migration}

The Canadian government's responses to international events causing forced migration has often been applauded internationally. These responses, however, have not come as a result of a long history of advanced planning and anticipatory policy, but almost always as temporary or "special measures." Special measures remain an important piece of Canada's overall migration policy. Special measures pro grams were implemented for refugee crises in Lebanon in 1979, Poland in 1980, El Salvador in 1981, Sri Lanka in 1983, China in 1989, Kosovo in 2000, Haiti in 2010, and most recently as a response to the catastrophe that followed Typhoon Haiyan in the Philippines. Just like these past events, a similar confluence of international and domestic influences continues to play an important role in determining which refugee crises receive formal policy attention. It is notable, then, that not every major incidence of forced migration elicits a Canadian response. The lack of a significant Canadian response to humanitarian crises in Afghanistan and parts of sub-Saharan Africa are notable examples.

Although civil war, ethnic conflict, and environmental disasters have ravaged Afghanistan and several countries in central Africa and the eastern horn of Africa, Canada has not put in place clear migration policies to aid in the repeated refugee crises affecting these countries or regions. The Canadian government has repeatedly maintained that the solution to Africa's problems "can only be found in Africa, by Africans."35 Perhaps political differences, foreign government influence, or some other form of bias may explain Canada's unwillingness to accept significant numbers of refugees from Afghanistan and African countries. For example, in 2011, the worst drought in 60 years, widespread famine, and persistent conflict displaced 200,000 Somalis into Kenya. ${ }^{36}$ Unlike in the case of the earthquake in Haiti, however, the Canadian government did not create any temporary special measures to assist Somali refugees to receive expedited services or processing, despite being home to one of the highest concentrations of Somalis outside of Somalia in the world. Financial assistance was provided to help with food relief, but not to facilitate migration. No policies such as the Temporary Suspension of Removals that were used after the Haitian earthquake or special immigration measures were implemented as part of its humanitarian response to the crisis. Canada's policy regarding African refugees generally corresponds with the United Nations policy on refugee resettlement, which advocates for the use of third-country resettlement only as a last resort, ${ }^{37}$ preferring instead the durable solutions of repatriation and local integration when responding to humanitarian crises.

A number of factors internal and external to Canada explain its response to incidences of forced migration. Internally, ethnic or cultural communities and their influence or role in Canadian society; domestic political and social advocacy, national and provincial political ideology and affinity for the international incident, and the traction of an incident in the media all seem significant factors driving national response. But as we have noted in relation to more recent global events, particularly in sub-Saharan Africa, the weight that these internal factors have on the national response is not clear, but is certainly worthy of future investigation. For example, under what conditions is a national government susceptible to domestic pressure and advocacy? This question is also important when considering the external factors that drive the Canadian national response. Under what conditions, for example, will the Canadian government reach out to or engage in an organized international response to an incidence of environmental migration or widespread persecution? Is national pressure on Canada, vis-à-vis another nation-state, more powerful than pressure from the UNHCR? Again, future research that examines a number of cases may be able to unpack this question more fully. Ultimately, the factors that push, persuade, or provide incentives for the national government to respond to environmental and non-environmental incidents are wide ranging. But what does remain consistent in most cases is that responses to forced displacement in Canada are reactive. Returning to the primary focus of this paper, the question that remains to be answered is, what does the study of the Canadian response to international migration emergencies and displacements contribute to an understanding of the links between national immigration policy and environmental migration?

It is difficult to generalize; nonetheless, the preceding discussion reveals useful insights relevant to issues of environmental migration. First, the history of migration policy (whether related to environmental events or not) provides important lessons about national humanitarian responses to environmental migration. The causes and consequences of displacement are complex, requiring input from a wide range of policy areas; nevertheless, it seems clear that Canada and a majority of other Western countries believe that immigration policy has a seat at the table in debates regarding the appropriate response to forced migration-environmentally caused or otherwise. Be it refugees fleeing the violent oppression of a dictatorial government or Haitians seeking to rebuild their lives after an earthquake, 
facilitating the efforts of people trying to escape dangerous circumstances ought to be a key part of the policy discussion.

Second, immigration policy is not static and does not exist in a vacuum. Every government will have its own agenda and priorities regarding humanitarian responses; they are, nonetheless, subject to a complex interplay of interests, both domestic and international. For example, despite Canada's significant level of involvement in the response to Haiti's environmental migrants in 2010, the relief efforts required the contributions of various international organizations and foreign governments, each with its own particular set of objectives, in addition to the resolve of the Haitian people themselves. Environmental migration is characterized by its interrelations with other social, political, security, and economic issues. The complexity and scale of environmental migration events requires that an effective response have the widespread support of the international community. In Canada, allied foreign governments and intergovernmental organizations (particularly the UNHCR) have been influential in determining the direction of Canada's migration policy. But their influence cannot be generalized, given the variation in Canadian response to various international events. The current level of support for environmental migrants is not dependent solely on the policy direction of any individual nation or external pressure. Major changes to current Canadian practices regarding environmental migration will likely occur only if a significant number of like-minded countries within the international community deem it necessary. But as the example of Canada's withdrawal from the Kyoto Protocol reveals, national interests do not always follow international norms. Each government is different and weighs the value of international engagement and cooperation differently, and usually on a case-by-case basis. Hence, Canadian policy-makers and the Canadian government must consider whether they wish to lead or follow international action on the issue of environmental migration. In 2012, for example, Norway and Switzerland announced their intent to formally create a global office and initiative to respond to environmental refugees. Named after the first UN high commissioner of refugees, Fridtjof Nansen, the Nansen Initiative "aims to address the legal and protection gap for people displaced across borders owing to environmental change and extreme weather events." 38

Finally, and perhaps most importantly, Canadian immigration policy offers interesting lessons regarding the future direction of environmental migration policy. In the short term, it is likely that governments will continue to respond to incidences of environmental migration using reactive, ad hoc, and temporary measures. The history of refugee policy in Canada demonstrates that special measures and ad hoc responses are the norm, while the formal protections offered to refugees as defined by the refugee convention are an exception to this standard practice. The international refugee regime was borne out of the particular circumstances of forced migration that arose during and after the Second World War. Environmental migration has yet to have an analogous impact on Western nations, and while there are promising signs that the international community is willing to talk more openly about the need to respond to the issue, without a comparable level of disruption, it seems unlikely that a response of a similar magnitude will occur in the near future. Given that global levels of forced migration due to environmental change and incidents are expected to continue and increase, and that Canada will be expected to be an international partner and willing migrant-receiving nation, it would seem pragmatic, if not ethical, to be part of the global solution to ensure that reliability, consistency, and predictability are strong principles underlying a global response to environmental migration events. Hence, for Canada, the question remains whether the country will take a lead role in the global debate about future responses to environmental migration or whether it will be satisfied relying on temporary measures.

\section{Notes}

1. Kofi Annan, "Address on the Closing of the International Decade for Natural Disaster Reduction" (paper presented at the International Decade for Natural Disaster Reduction, Geneva, 1999), www.unisdr.org/files/31468_programme forumproceedings.pdf.

2. Michelle Yonetani, Displacement Due to Natural HazardInduced Disasters: Global Estimates for 2009 and 2010 (Geneva: Internal Displacement Monitoring Centre, 2011).

3. Koko Warner, Charles Ehrhart, Alex Sherbinin, and Susan Adamo, In Search of Shelter: Mapping the Effects of Climate Change on Human Migration and Displacement (New York: Care International, 2009).

4. Yonetani, Displacement.

5. United Nations High Commissioner for Refugees, UNHCR: Global Trends 2010 (Geneva: UNHCR, 2010).

6. Koko Warner, "Global Environmental Change and Migration: Governance Challenges," Global Environmental Change 20, no. 3 (2010): 402.

7. Foresight: Migration and Global Environmental Change, Final Project Report (London: Government Office for Science, 2011).

8. Citizenship and Immigration Canada, "Guidelines for Priority Processing in the Event of Disaster Situations," Operational Bulletin 83, 2008, http://www.cic.gc.ca/english/ resources/manuals/bulletins/2008/ob083.asp.

9. United Nations University, "UN Day for Disaster Reduction," 2005, http://www.ehs.unu.edu/file/get/3916. 
10. Norman Myers, "Environmental Refugees: A Growing Phenomenon of the 21st Century," Philosophical Transactions of the Royal Society of London, Series B: Biological Sciences 357, no. 1420 (2002): 609-13.

11. Essam El-Hinnawi, Environmental Refugees (Nairobi, Kenya: United Nations Environmental Programme, 1985), 4 .

12. Convention relating to the Status of Refugees, [parties], 28 July 1951, 189 U.N.T.S. 150, Can. T.S. 1969/6 (entered into force 22 April 1954, accession by Canada 2 September 1969), http://www.unhcr.org/protect/PROTECTION/3b73b0d63 .pdf.

13. Diane C. Bates, "Environmental Refugees? Classifying Human Migrations Caused by Environmental Change," Population and Environment 23, no. 5 (2002): 465-77.

14. Ibid.

15. Richard Black, "Environmental Refugees: Myth or Reality?, UNHCR Working Paper, no. 34 (Geneva: UNHCR, 2001).

16. Rafael Reuveny, "Ecomigration and Violent Conflict: Case Studies and Public Policy Implications," Human Ecology 36, no. 1 (2008): 1-13.

17. United Nations Commission on Human Rights, Guiding Principles on Internal Displacement, 2nd ed. (Geneva: UNCHR, 1998), http://www.unhcr.org/43celcff2.html.

18. International Organization for Migration, "Migration and the Environment" (paper presented at the 94th Council Session, Geneva, 2007).

19. Koko Warner, "Global Environmental Change and Migration: Governance Challenges," Global Environmental Change 20, no. 3 (2010): 402.

20. C. Boano, R. Zetter, and T. Morris, Environmentally Displaced People, policy briefing (Oxford: Refugee Studies Centre, Oxford Department of International Development, 2008); Suzette Brooks Masters, "Environmentally Induced Migration: Beyond a Culture of Reaction," Georgetown International Environmental Law Review 14, no. 855 (2000): 855-79; Norman Myers, "Environmental Refugees: A Growing Phenomenon of the 21st Century," Philosophical Transactions of the Royal Society of London, Series B: Biological Sciences 357 no. 1420 (2002): 609-13.

21. Douglas S. Massey, W. Axinn, and D. Ghimire, "Environmental Change and Out-Migration: Evidence from Nepal," Population and Environment 32, nos. 2-3 (2009): 109-36.

22. Boano, Zetter, and Morris, Environmentally Displaced People.

23. Citizenship and Immigration Canada, "Backgrounder: Designated Countries of Origin," 2013, http://www .cic.gc.ca/english/department/media/backgrounders /2012/2012-11-30.asp.

24. Canadian Council for Refugees, "Concerns about Changes to the Refugee Determination System," 2012, http://ccrweb .ca/en/concerns-changes-refugee-determination-system.

25. David Brooks, “The Underlying Tragedy," New York Times, 15 January 2010.

26. Myers, "Environmental Refugees."
27. CitizenshipandImmigration Canada, OperationalBulletins 2011, http://www.cic.gc.ca/english/resources/manuals/ bulletins/2011/index.asp.

28. Citizenship and Immigration Canada, "Guidelines for Priority Processing."

29. Jane Taber, "With One Last Flight to Haiti, Operation Stork Winds Down," Globe and Mail, 29 January 2010, http://www theglobeandmail.com/news/politics/ottawa-notebook/ operation-stork-winds-down/article1450042/.

30. Citizenship and Immigration Canada, Policies and Regulations: Fact Sheets on Refugee Issues (2006), http://www.parl .gc.ca/HousePublications/Publication.aspx?DocId=29697 $55 \&$ Language $=\mathrm{E} \&$ Mode $=1 \&$ Parl $=39 \&$ Ses $=1 \&$ File $=42 \# \mathrm{p}$ art5.

31. Michael Blanchfield, "Canada Boosts Aid to Pakistan, Still Well Short of Haiti Response," Toronto Star, 14 September 2010, http://www.thestar.com/news/world/pakistan/ article/860789-canada-boosts-aid-to-pakistan-still-well -short-of-haiti-response.

32. Canada earned a positive international reputation for responding to some refugee events historically, such as the Hungarian refugee crisis of 1956, when Canada admitted over 37,000 Hungarians on humanitarian grounds following the Soviet invasion of Hungary, or the Indochinese refugee crisis of 1975 after which Canada had admitted 60,000 Vietnamese refugees by 1980. In fact, in 1986, the Nansen Refugee Award, given "in recognition of extraordinary and dedicated service to refugees ... the most prestigious honour conferred by United Nations High Commissioner for Refugees (UNHCR)," was awarded to the Canadian people as a whole. See Ninette Kelley and Michael J. Trebilcock, The Making of the Mosaic: A History of Canadian Immigration Policy (Toronto: University of Toronto Press, 1998); Michael Boyd and Monica Vickers, "100 Years of Immigration in Canada," Canadian Social Trends 58 (Autumn 2000): 2-12; Valerie Knowles, Strangers at Our Gates, rev. ed. (Toronto: Dundurn, 2007); Gil Loescher, Alexander Betts, and James Milner, The United Nations High Commissioner for Refugees (UNHCR): The Politics and Practice of Refugee Protection into the Twenty-First Century (New York: Routledge, 2008); United Nations High Commissioner for Refugees, "Nansen Refugee Award," http://www .unhcr.org/pages/49c3646c461.html.

33. World Meteorological Organization, The Global Climate 2001-2010: A Decade of Climate Extremes (Geneva: WMO, 2013), http://library.wmo.int/opac/index .php?lvl=notice_display\&id $=15110$.

34. Foresight, Final Project Report.

35. Ibid., 411.

36. United Nations High Commissioner for Refugees, "Crisis in the Horn of Africa," 2011, http://www.unhcr.org/ pages/4e1ff4b06.html.

37. United Nations High Commissioner for Refugees, Resettlement Handbook (Geneva: UNHCR, 2011), http://www .unhcr.org/4a2ccf4c6.html. 
38. UN News Centre, "New UN Report Spotlights Role of Climate Change in Driving People from Their Homes," 2012 http://www.un.org/apps/news/story.asp?NewsID=42298\# .USt-UqX3xE8.

Eric Omeziri is a graduate of Ryerson University's Master of Arts program in Immigration and Settlement Studies. He works in refugee determination in the public sector. The author may be contacted at eric.omeziri@alumni.ryerson.ca.
Christopher Gore is an associate professor, Department of Politics and Public Administration, and an affiliate of the Environmental Applied Science and Management and Immigration and Settlement Studies graduate programs, Ryerson University. Dr. Gore is also the editor of Review of Policy Research: The Politics and Policy of Science and Technology, the official journal of the Science, Technology and Environmental Politics section of the American Political Science Association. The author may be contacted at chris. gore@politics.ryerson.ca. author(s) are credited and the original publication in Refuge: Canada's Journal on Refugees is cited. 
(C) Eric Omeziri and Christopher Gore, 2014. This open-access work is licensed under a Creative Commons Attribution-NonCommercial 4.0 International License, which permits use, reproduction and distribution in any medium for non-commercial purposes, provided the original author(s) are credited and the original publication in Refuge: Canada's Journal on Refugees is cited. 